\title{
Recovery in a Patient with Locked-In Syndrome
}

\author{
Brian Silver, Kavita M. Grover, Ximena Arcila, Panayiotis D. Mitsias, \\ Susan M. Bowyer, Michael Chopp
}

\begin{abstract}
Background and Purpose: Sildenafil citrate has been shown to enhance neurogenesis, angiogenesis, synaptogenesis, and neurological outcome by augmentation of cyclic guanosine monophosphate (cGMP) levels in animal models of ischemic stroke. Whether sildenafil citrate may be helpful for recovery in human stroke is unknown at this time. Methods: A 41-year-old woman with locked-in syndrome due to pontine infarction began receiving $150 \mathrm{mg}$ of oral sildenafil citrate daily on a compassionate use basis in August 2003 and continues treatment at this time. Magnetoencephalography (MEG) was performed at 12 and 17 months after stroke. Results: No serious adverse events have occurred. Significant milestone recoveries including standing, use of both arms, talking, and full return of swallowing have occurred, particularly after nine months of treatment. The MEG showed a significantly increased amplitude in the somatosensory cortex. Conclusion: Daily use of high dose sildenafil citrate appears to be safe in this patient with stroke resulting in locked-in syndrome. Further studies will be required to establish safety and efficacy.
\end{abstract}

RÉSUMÉ: Récupération chez une patiente atteinte du locked-in syndrome. Contexte et objectif: La neurogenèse, l'angiogenèse et la synaptogenèse sont stimulées par le citrate de sildenafil et l'issue neurologique est améliorée à cause de l'augmentation des niveaux de guanosine monophosphate cyclique (cGMP) chez des modèles animaux d'accident vasculaire cérébral ischémique. On ne sait pas si le citrate de sildenafil peut être utile dans la récupération d'un accident vasculaire cérébral chez l'humain. Méthodes: Une femme âgée de 41 ans, atteinte du locked-in syndrome dû à un infarctus du pont, a commencé à recevoir $150 \mathrm{mg}$ de citrate de sildenafil per os quotidiennement en août 2003 (accès spécial). Elle prend toujours cette médication. Une magnéto-encéphalographie (MEG) a été effectuée 12 et 17 mois après l'infarctus. Résultats: Elle n'a présenté aucun incident thérapeutique. Des étapes importantes au point de vue récupération ont été franchies : la station debout, l'utilisation des deux bras, la parole et la déglutition. Ceci était plus évident après neuf mois de traitement. On a observé une augmentation significative de l'amplitude dans le cortex somesthésique à la MEG. Conclusion: La prise quotidienne d'une dose élevée de citrate de sildenafil semble sûre chez cette patiente atteinte du locked-in syndrome suite à un accident vasculaire cérébral. Sa sécurité et son efficacité devront toutefois faire l'objet d'études plus poussées.

Can. J. Neurol. Sci. 2006; 33: 246-249

Locked-in syndrome is defined as quadriplegia and anarthria with preserved consciousness. ${ }^{1,2}$ Initial research into the syndrome found a mortality of $60 \%$, and is higher among patients with vascular etiologies $(67 \%)$ compared with other etiologies $(41 \%) .^{3} \quad$ More recently, Casanova and colleagues ${ }^{4}$ reported that early intensive multidisciplinary rehabilitation reduced mortality to $14 \%$ ( 2 of 14 patients), but only $21 \%$ of patients ( 2 of 14) achieved significant motor recovery.

Mammalian studies demonstrate that neurogenesis can occur in the adult brain, beginning in the dentate gyrus and subventricular zone. ${ }^{5}$ Pharmacologic increase of cyclic guanosine monophosphate (cGMP), as occurs with sildenafil citrate, has been shown to induce neurogenesis, angiogenesis, and synaptogenesis in young and old animal models following stroke. ${ }^{6-8}$ We report a patient with locked-in syndrome who has had significant motor recovery and has received oral sildenafil citrate daily on a compassionate basis.

\section{Case Report}

In July 2003, a 41-year-old woman with a history of headaches developed vertigo immediately after chiropractic neck manipulation to

From the Department of Neurology, Henry Ford Health System (BS, KMG, XA, PDM, SMB, MC); Wayne State University (BS, PM), Detroit, MI; Oakland University (SMB, MC), Rochester, MI, USA.

Received August 4, 2005. AcCePted in FinAl FORM November 26, 2005. Reprint requests to: Brian Silver, Department of Neurology, Henry Ford Hospital, 2799 West Grand Boulevard, K-11, Detroit, Michigan, 48202, USA. 
relieve symptoms. Forty-eight hours after onset of symptoms, she was found by her husband on the floor of her home unable to move her limbs or respond verbally. She was seen at an outside hospital initially and was transferred to our facility four days after symptom onset. Her examination showed her to be alert and fully oriented. Her only means of communication was through vertical eye movements. She had no movement of the lower face, tongue, or limbs. She was able to appreciate all sensory modalities throughout. An MRI on day 5 after onset showed near total infarction of the pons with sparing of a small ventral crescent (Figure 1a and 1b). Angiography showed bilateral vertebral artery dissections at the C1-C2 level (Figure 2a and 2b). Flow was absent in the majority of the basilar artery except at the tip which was fed by the right posterior communicating artery.

She was diagnosed as having locked-in syndrome. The patient and family expressed a strong desire to pursue non-standard treatments, and gave verbal and written consent to use sildenafil citrate. A request to the hospital compassionate use therapeutics committee was approved.
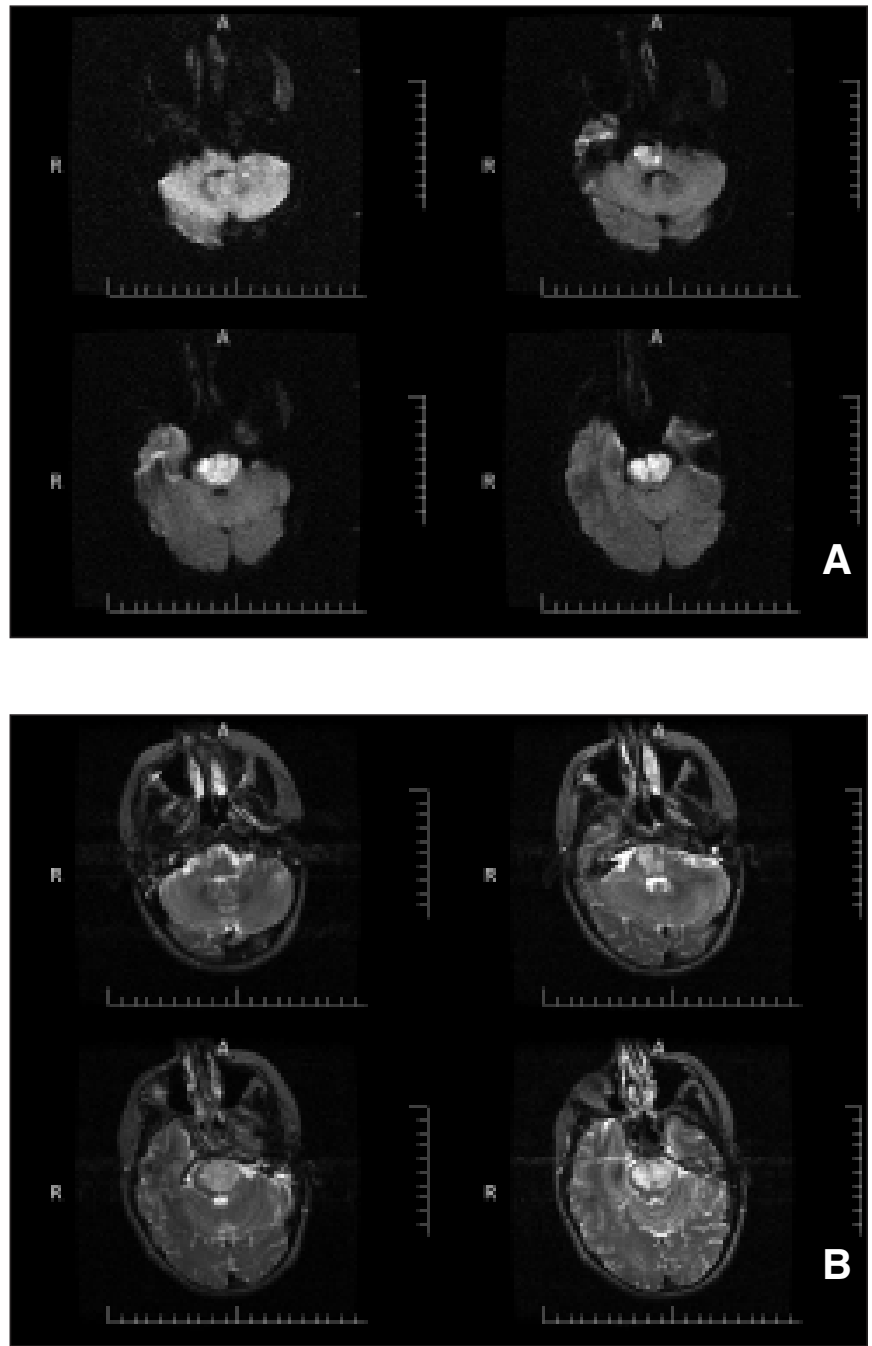

Figure 1: Near total infarction of the pons is shown on (a) diffusionweighted and (b) T2-weighted imaging on day 5 after stroke onset.
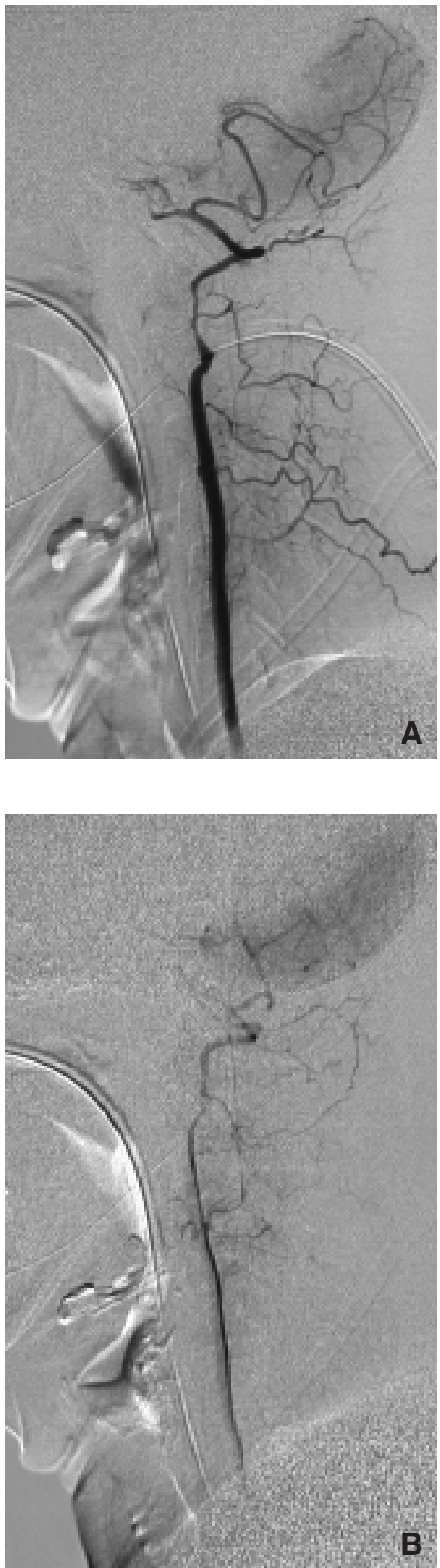

Figure 2: Dissections of (a) right and (b) left vertebral arteries at the C1-C2 levels with absence of flow in the basilar artery is shown on digital subtraction angiography. 


\section{A. Stimulus to the Left Digit}

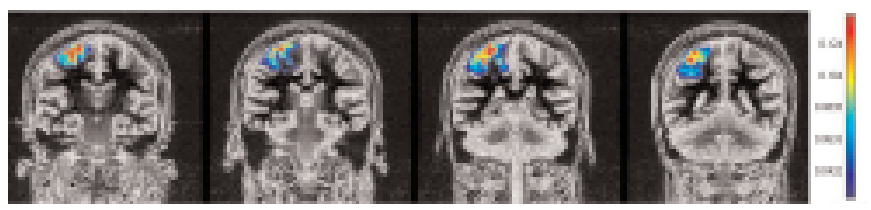

B. Stimulus to the Left Digit

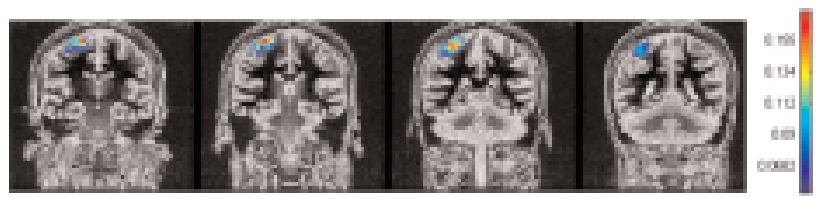

Stimulus to the Right Digit

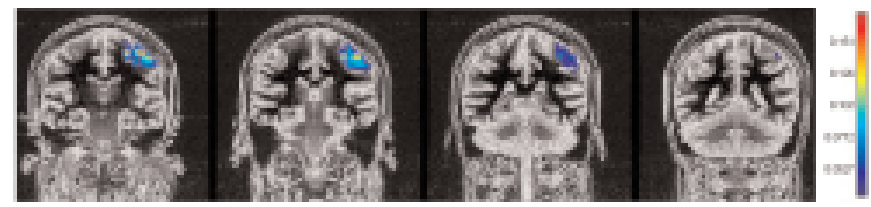

Stimulus to the Right Digit

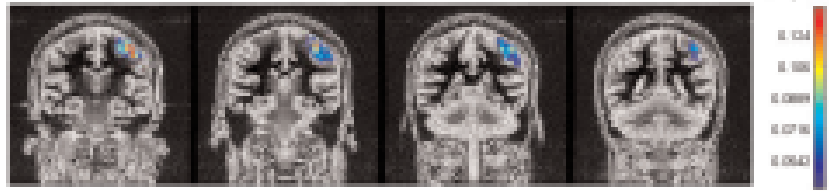

Figure 3: Magnetoencephalography at (a) 12 months showed a cortical amplitude in the somatosensory cortex (0.165 nanoAmp Meters) which extended anteriorly and was three times that of a normal aged matched control (not shown). Magnetoencephalography at (b) 17 months showed an even higher cortical amplitude (0.210 nanoAmp Meters).

Because the most favorable dose in basic science studies correlated with a dose of $10 \mathrm{mg} / \mathrm{kg}$, the serum equivalent in human studies was chosen for dosing purposes. A dose of $3 \mathrm{mg} / \mathrm{kg}$ in animal studies is equivalent to roughly $50 \mathrm{mg}$ in human studies (Pfizer Corp., personal communication). Ten days after symptom onset, $150 \mathrm{mg}$ orally per day was given, divided into $50 \mathrm{mg}$ in the morning and $100 \mathrm{mg}$ in the evening. She continues this dose to the present time.

She was discharged to an in-patient rehabilitation facility one month after admission where she received approximately three hours daily of physical, occupational, and speech therapy for nine months. One month after admission to hospital, she was able to perform side-to-side head movement. At two months, she was able to lift her head off the bed, protrude her tongue, and perform slight movements of the lower face. At four months, she was able to raise her right arm and open and close her right hand to a limited extent. She also was able to perform small movements of toes and produce high pitched vocalizations. At nine months, she was able to operate a motorized wheelchair with her right hand, send e-mails, and lift her left arm. She was also able to produce high-pitched speech with moderate to severe dysarthria. At this time (two years after onset), she is able to stand unassisted for 20 minutes while holding a walker, eat all foods, comb her hair, brush her teeth, speak while lying flat, write with a regular pen, control continence, and requires assistance with bathing and dressing.

Early side effects thought to be associated with treatment included mild hypotension (approximate drop in systolic blood pressure of 20 mmHg approximately $1-2$ hours after ingestion) and muscle cramping in her legs at doses above $100 \mathrm{mg}$ daily. Hypotension resolved in 1-2 months while muscle cramping continued for approximately 15 months.

Magnetoencephalography (MEG) has been previously shown to detect activated primary sensory cortical regions in stroke patients. ${ }^{9,10}$ Magnetoencephalography has also been used to localize the somatosensory evoked potential (SEP) response with the single equivalent current dipole (ECD) in stroke patients. ${ }^{9,10}$ We studied the current patient at delayed time points after stroke onset with MEG utilizing a current density technique known as MR-FOCUSS, which constrained the sources of SEP to the patient's cortical gray matter and was able to image extended sources unlike the ECD. ${ }^{11}$ MEG at 12 months showed an amplitude in the somatosensory cortex $(0.165$ nanAmp-Meter) (Figure 3a) that was three times that of a normal control (not shown). The region of activated cortex extended anteriorly beyond the region normally encompassing the sensory region. Another study at 17 months showed that the region of activity had reduced to a more focal area but with an even higher amplitude (0.210 nanoAmp-Meter) (Figure $3 b)$.

\section{Discussion}

Mortality related to locked-in syndrome appears to have reduced from approximately $80 \%$ to $20 \%$ over the last 20 years and may be related to early aggressive rehabilitation. ${ }^{3,4}$ Nevertheless, significant physical disability is seen in approximately $80 \%$ of survivors, and has not markedly changed over the same time period.

The patient described above showed considerable improvement in motor function following near-total pontine infarction on MRI coincident with administration of sildenafil citrate. Based on current classification schemes, her most recent functional status would be considered a moderate recovery. ${ }^{3}$ Others have documented patients with locked-in syndrome due to presumed ventral pontine infarction who also regained considerable function. ${ }^{12-14}$

The MEG scan showed increased areas of neuronal activation outside the primary somatosensory areas consistent with previous MEG findings in stroke patients., ${ }^{9,10}$ This finding suggests the possibility of using MEG as a means of evaluating functional recovery after stroke. Amplitudes continued to increase from the 12- to 17-month MEG studies supporting the idea that recovery may continue well beyond one year.

Motor recovery following stroke is thought to peak within the first six months after stroke and be predictive of final outcome $e^{3,4}$ yet this patient continues to achieve milestones in motor function well beyond that period. The precise mechanisms by which sildenafil citrate may improve neurological function in humans 
are unknown. When this agent is administered to rodents after stroke, there is increased brain plasticity, via a cGMP pathway, which includes angiogenesis, neurogenesis and synaptogenesis $^{6-8}$ without a reduction in infarct volume. Future studies will be required to establish safety and efficacy.

\section{ACKNOWLEDGEMENT}

We thank Sarah Whitehouse for reviewing the manuscript.

\section{Disclosure}

Dr. Chopp has received funding from Pfizer pharmaceuticals for basic science studies.

Dr. Chopp received permission from Pfizer pharmaceuticals to reveal the serum-dose relationship of sildenafil citrate in the rodent.

\section{REFERENCES}

1. Smith E, Delargy M. Locked-in syndrome. Br Med J. 2005;330:406-9.

2. Leon-Carrion J, van Eeckhout P, Dominguez-Morales Mdel R, Perez-Santamaria FJ. The locked-in syndrome: a syndrome looking for a therapy. Brain Inj. 2002;16:571-82.

3. Patterson JR, Grabois M. Locked-in syndrome: a review of 139 cases. Stroke. 1986;17:758-64.

4. Casanova E, Lazzari RE, Lotta S, Mazzucchi A. Locked-in syndrome: improvement in the prognosis after an early intensive multidisciplinary rehabilitation. Arch Phys Med Rehabil. 2003;84:862-7.
5. Gould E, Reeves AJ, Graziano MS, Gross CG. Neurogenesis in the neocortex of adult primates. Science. 1999;286:548-52.

6. Zhang R, Wang Y, Zhang L, Zhang Z, Tsang W, Lu M, et al. Sildenafil (Viagra) induces neurogenesis and promotes functional recovery after stroke in rats. Stroke. 2002;33:2675-80.

7. Zhang R, Wang L, Zhang L, Chen J, Zhu Z, Zhang Z, et al. Nitric oxide enhances angiogenesis via the synthesis of vascular endothelial growth factor and cGMP after stroke in the rat. Circ Res. 2003;92:308-13.

8. Zhang L, Zhang RL, Wang Y, Zhang C, Zhang ZG, Meng H, et al. Functional recovery in aged and young rats after embolic stroke: treatment with a phosphodiesterase type 5 inhibitor. Stroke. 2005;36:847-52.

9. Rossini PM, Tecchio F, Pizzella V, Lupoi D, Cassetta E, Pasqualetti P. Interhemispheric differences of sensory hand areas after monohemispheric stroke: MEG/MRI integrative study. Neuroimage. 2001;14:474-85.

10. Gallien P, Aghulon C, Durufle A, Petrilli S, de Crouy AC, Carsin M, et al. Magnetoencephalography in stroke: a 1-year follow-up study. Eur J Neurol. 2003;10:373-82.

11. Moran JE, Bowyer SM, Tepley N. Multi-Resolution FOCUSS: a source imaging technique applied to MEG data. Brain Topogr. 2005; $18: 1-17$

12. Haig AJ, Katz RT, Sahgal V. Mortality and complications of the locked-in syndrome. Arch Phys Med Rehabil. 1987;68:24-7.

13. McCusker EA, Rudick RA, Honch GW, Griggs RC. Recovery from the 'locked-in' syndrome. Arch Neurol. 1982;39:145-7.

14. Khurana RK, Genut AA, Yannakakis GD. Locked-in syndrome with recovery. Ann Neurol. 1980;8:439-41. 